\title{
EFFECT OF EXTERNAL STRESS ON THE POST-AGING MECHANICAL PROPERTIES OF ROLLED MAGNESIUM ALLOYS
}

\author{
Mustafa MISIRLI, Ali HOSSEINZADEH, Guney Guven YAPICI \\ Mechanical Engineering Department, Ozyegin University, Istanbul, Turkey, \\ mustafa.misirli@ozu.edu.tr, ali.hosseinzadeh@ozu.edu.tr, quven.yapici@ozyegin.edu.tr
}

https://doi.org/10.37904/metal.2020.3590

\begin{abstract}
In the current study the effects of conventional aging and stress aging on the microstructure and mechanical behavior of warm rolled AZ31 magnesium alloy were investigated. Tensile experiments revealed that the ultimate tensile strength (UTS) of the as-received AZ31 increased up to $300 \mathrm{MPa}$ after $24 \mathrm{~h}$ aging at $120^{\circ} \mathrm{C}$, with a $2 \%$ reduction in ductility. Moreover, yield strength of the rolled and stress aged sample at $120{ }^{\circ} \mathrm{C}$ under an external stress of $50 \mathrm{MPa}$ and only for $1 \mathrm{~h}$ was improved to $240 \mathrm{MPa}$. Microstructural observations demonstrate that the grain growth firstly reduced the strength of rolled condition while improving the strain at failure. This was followed by the nucleation of recrystallized grains, enhancing the UTS with acceptable ductility. In addition, fracture surface analysis of stress aged samples demonstrated nucleation-controlled fracture mechanisms with deeper void structures as a ductile characteristic.
\end{abstract}

Keywords: Magnesium, thermo-mechanical, rolling, aging, microstructural evolution, mechanical behavior

\section{INTRODUCTION}

Magnesium is one of the most plentiful elements on the planet and the third most abundant element dissolved in seawater, with an estimated concentration of $0.14 \%[1,2]$. Recently, magnesium alloys especially $A Z$ series, are evaluated to be suitable nominates for structural components serving as an alternative for heavier aluminum and steel [3-5]. These alloys represent noteworthy properties such as low density, high corrosion resistance, high strength as well as appropriate machinability, weldability, and castability, etc. [6,7]. Nevertheless, low formability of magnesium alloys restricts processing such as rolling, extrusion, and metal forming, so it limits their applications in industry $[8,9]$. The major reason of the low ductility is the insufficient slip systems in the hexagonal close-packed (HCP) crystal structure $[10,11]$.

Many works have been performed for the advancement of thermo-mechanical treatments for developing the mechanical behavior of magnesium alloys to eliminate the formability limitation and spread the range of their applications in various engineering structures $[12,13]$. Warm rolling is one of the most common approaches for improving the strength of $A Z$ series of magnesium alloys. For instance, Jeong et al. [14] observed a significant grain refinement of $A Z 31$ after $50 \%$ warm rolling at $200{ }^{\circ} \mathrm{C}$, producing a fine grain structure of around $7 \mu \mathrm{m}$. Besides, they investigate the effect of warm rolling on the texture of AZ31 in detail. Aging is another technique for mechanical property improvement, taking advantage of precipitation-induced strengthening. The influence of various post heat treatments on the cyclic mechanical behavior of AZ series was investigated [15]. $\mathrm{Mg}_{17} \mathrm{Al}_{12}$ precipitates were commonly detected after the application of $\mathrm{T} 5$ and $\mathrm{T} 6$ heat treatments. Still, it has to be noted that age-hardening of magnesium alloys is not as effective as that for aluminum alloys due to the lower volume fraction of precipitates.

In spite of the previous studies on the thermo-mechanical processing of AZ31, there is a lack of know-how concerning the influence of external stress during heat treatment on the mechanical response. This work 
investigates in a comparative manner, the influence of warm rolling followed by conventional aging and stress aging on the mechanical behavior of AZ31 magnesium alloy, discussing the relations among the microstructure evolution, tensile behavior, and fracture surface analysis.

\section{EXPERIMENTAL PROCEDURE}

$4 \mathrm{~mm}$ thick AZ31 slabs 3.32Al-2.4Zn-0.84Mn-Mg bal. (wt\%) were utilized for the warm rolling process. Asreceived (AR) material with the annealed condition was homogenized at $400{ }^{\circ} \mathrm{C}$ for $3 \mathrm{~h}$. A systematic warm rolling process was applied to reduce the thickness of plates, $75 \%$ of initial thickness. The unidirectional rolling process was done at $300{ }^{\circ} \mathrm{C}$ with the thickness reduction rate of $5 \%$ per pass. The aging process was carried out inside a vacuum furnace to prevent oxidation. Furthermore, a custom stress aging apparatus was designed and manufactured to apply $50 \mathrm{MPa}$ external stress on the samples throughout the aging process.

The tensile specimens were electro-discharged along the rolling direction. The samples of each condition after metallographic preparation etched by immersing in a solution of $5 \mathrm{gr}$ picric acid, $10 \mathrm{ml}$ acetic acid, $70 \mathrm{ml}$ ethanol and $10 \mathrm{ml}$ distilled water. Dog-bone-shaped tensile specimens (gage length $15 \mathrm{~mm}$ ) were used for tensile tests taking place at room temperature and at a strain rate of $0.001 \mathrm{~s}^{-1}$ by a servo-hydraulic Instron mechanical test frame. Finally, secondary electron micrographs were obtained inside a ZEISS scanning electron microscope (SEM) for studying the fracture mechanisms of samples following tensile loading.

\section{RESULTS AND DISCUSSION}

\subsection{Tensile tests}

Figure 1 illustrates the tensile test results of AZ31 after various thermo-mechanical processing. Despite the low YS of the AR condition (166 MPa) due to the grain growth during annealing homogenization treatments, the ultimate tensile strength (UTS) reached to $250 \mathrm{MPa}$. Also, the failure strain of AR condition was restricted to $9 \%$ due to the inadequate slip modes. As shown in Figure 1a, UTS of AR sample elevated to $291 \mathrm{MPa}$ after rolling. Additional aging treatments were applied on the rolled slabs to improve the strength and ductility.
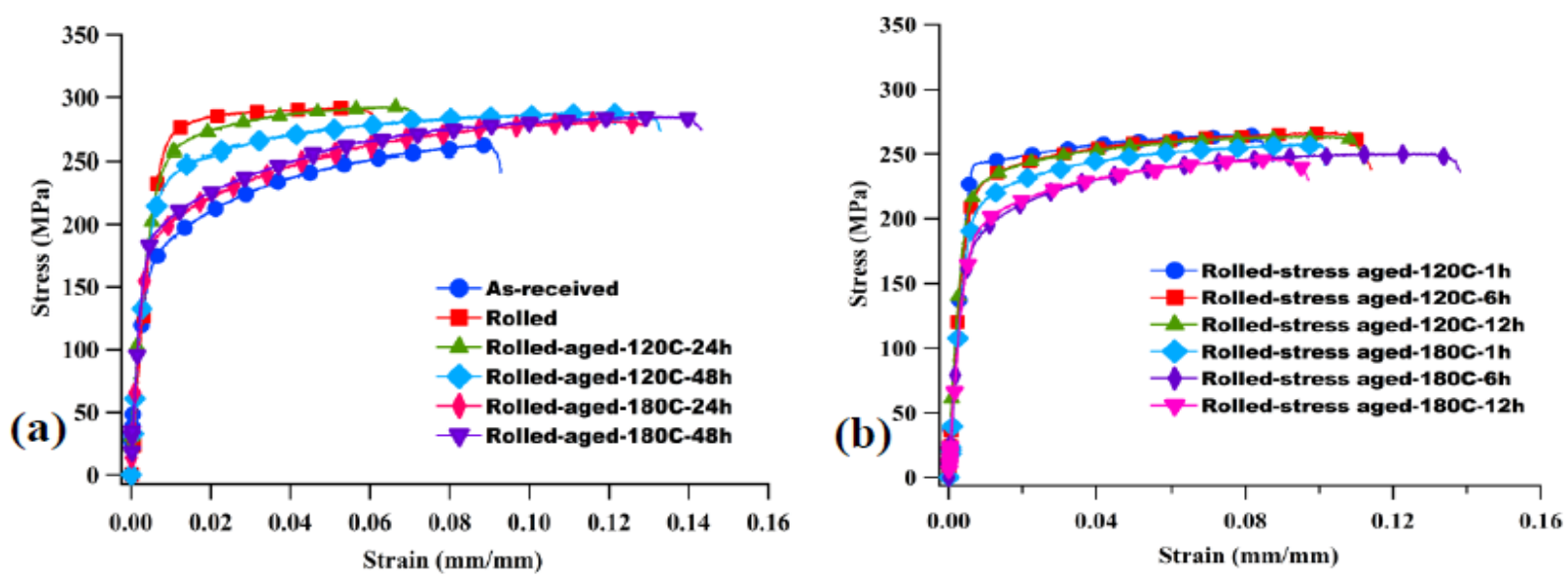

Figure 1 Tensile test results of AZ31 for different conditions of (a) AR, rolled, and conventional aged samples; (b) stress aged samples

The stress-strain curves revealed that after $24 \mathrm{~h}$ aging at $120^{\circ} \mathrm{C}$ the $\mathrm{YS}$ of the sample decreased while the UTS and the ductility improved, in comparison with the rolled specimen. Also, after aging at $120^{\circ} \mathrm{C}$ for $48 \mathrm{~h}$ the ductility raised up to $13 \%$ with a notable loss in YS and an almost equal UTS. Comparable performance was observed for the samples, aged at $180^{\circ} \mathrm{C}$ for $24 \mathrm{~h}$ and $48 \mathrm{~h}$. The reduction of $\mathrm{YS}$ was more significant in 
comparison to the samples aged at $120^{\circ} \mathrm{C}$ (about $60 \mathrm{MPa}$ lower than rolled sample for both $24 \mathrm{~h}$ and $48 \mathrm{~h}$ ) due to the higher propensity for grain growth at $180^{\circ} \mathrm{C}$. On the other hand, Figure $1 \mathbf{b}$ demonstrates the tensile behavior of stress aged samples. Comparison of stress-strain curves of the stress aged samples with the conventional aged ones exposed that the strain hardening ability of rolled sample after stress aging was not recovered for both conditions. Moreover, after $6 \mathrm{~h}$ stress aging at both temperatures of $120{ }^{\circ} \mathrm{C}$ and $180^{\circ} \mathrm{C}$, the strength was not enhanced further due to the growth of the recrystallized grains.

\subsection{Microstructural observation of conventional aged samples}

Figures 2 and 3 exhibit the microstructure of AR, rolled, and rolled plus conventional aged at $120{ }^{\circ} \mathrm{C}$ and $180^{\circ} \mathrm{C}$, respectively. The average grain size of the AR sample was approximately $44 \mu \mathrm{m}$, while the grain size significantly decreased after $75 \%$ rolling at $300{ }^{\circ} \mathrm{C}$ and refined down to about $8 \mu \mathrm{m}$ (Figure 1b). This level of grain refinement is attributed to high strain imposed during plastic deformation up to $75 \%$ rolling reduction.
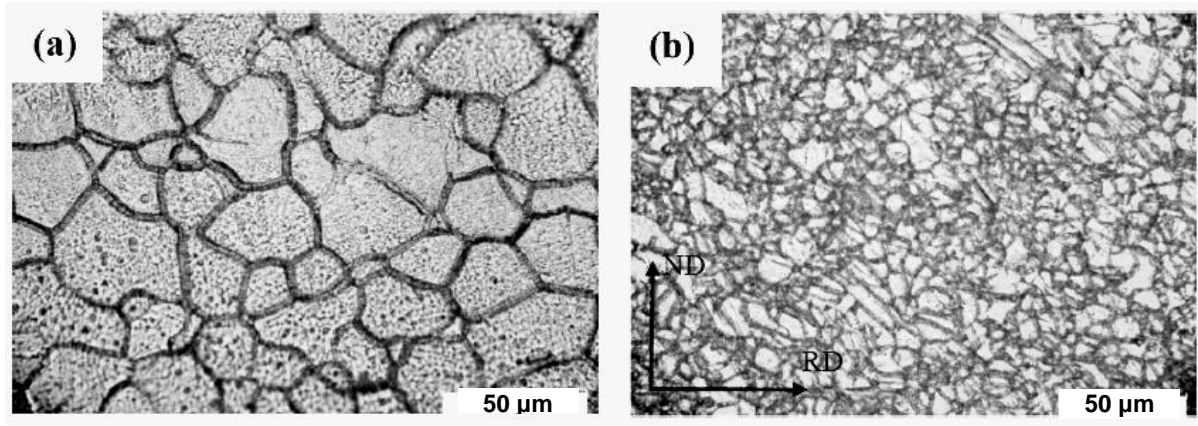

Figure 2 OM of AZ31 for (a) AS and (b) 75\% warm rolled conditions.
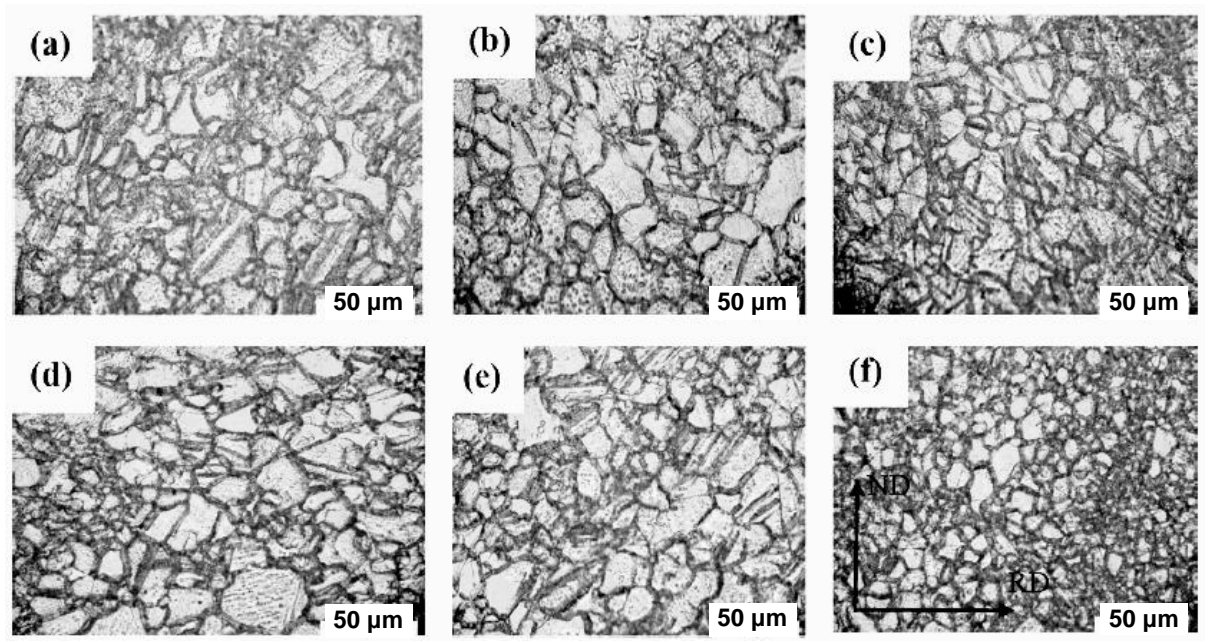

Figure $3 \mathrm{OM}$ of $\mathrm{AZ31}$ after $75 \%$ warm rolling and conventional aging at (a) $120^{\circ} \mathrm{C}$ for $12 \mathrm{~h}$, (b) $120^{\circ} \mathrm{C}$ for 24 $\mathrm{h}$, (c) $120^{\circ} \mathrm{C}$ for $48 \mathrm{~h}$, (d) $180^{\circ} \mathrm{C}$ for $12 \mathrm{~h}$, (e) $180^{\circ} \mathrm{C}$ for $24 \mathrm{~h}$, (f) $180^{\circ} \mathrm{C}$ for $48 \mathrm{~h}$

The microstructure of conventional aged samples revealed grain growth after $12 \mathrm{~h}$ aging at $120^{\circ} \mathrm{C}$. Nucleation of recrystallized grains took place after $24 \mathrm{~h}$ aging resulting in restored strain hardening capability as exhibited by the tangent modulus of the stress-strain response. This is followed by the growth of recrystallized grains leading to decreased strength for longer durations of aging (Figures $\mathbf{3 a}, \mathbf{b}$ and $\mathbf{c}$ ). Moreover, Figures $\mathbf{3 d}$, $\mathbf{e}$ and $f$ show a similar trend for the samples after aging at $180^{\circ} \mathrm{C}$. However, the fraction of recrystallized grains for the sample conventionally aged at $180^{\circ} \mathrm{C}$ for $48 \mathrm{~h}$ was higher than that of the sample aged at $120^{\circ} \mathrm{C}$ which elevated the ductility of the former slightly. 


\subsection{Microstructural observation of stress aged samples}

The microstructure evolution of AZ31 for the different conditions of rolled plus stress aging is depicted in Figure 4. Nucleation of recrystallized grains took place after a relatively short period of $1 \mathrm{~h}$ which was considerably faster than the kinetics of conventional aging due to the positive influence of stress aging on the precipitation hardening of AZ31 [16]. The precipitation hardening for magnesium alloys arises from an aging treatment for a supersaturated solid solution at a temperature range of $100-300{ }^{\circ} \mathrm{C}$ [17]. The effect of Orowan strengthening due to nanoscale precipitation of $\beta-\mathrm{Mg}_{17} \mathrm{Al} \mathrm{l}_{12}$ phases on the tensile behavior of the $\mathrm{AZ}$ series magnesium alloys was investigated previously $[17,18]$. Furthermore, the presence of precipitates provides an opportunity to accelerate the nucleation of recystallized grains due to particle-stimulated nucleation (PSN). The yield strength of stress aged sample at $120^{\circ} \mathrm{C}$ for $1 \mathrm{~h}$ remained at about $240 \mathrm{MPa}$ as attributed to the pinning effect of precipitates that prevents the growth of recrystallized grains [19,20]. As shown in Figure 4a, for the samples stress aged at $180^{\circ} \mathrm{C}$, due to the rapid grain growth after $1 \mathrm{~h}$, the yield strength of the samples decreased to $200 \mathrm{MPa}$.
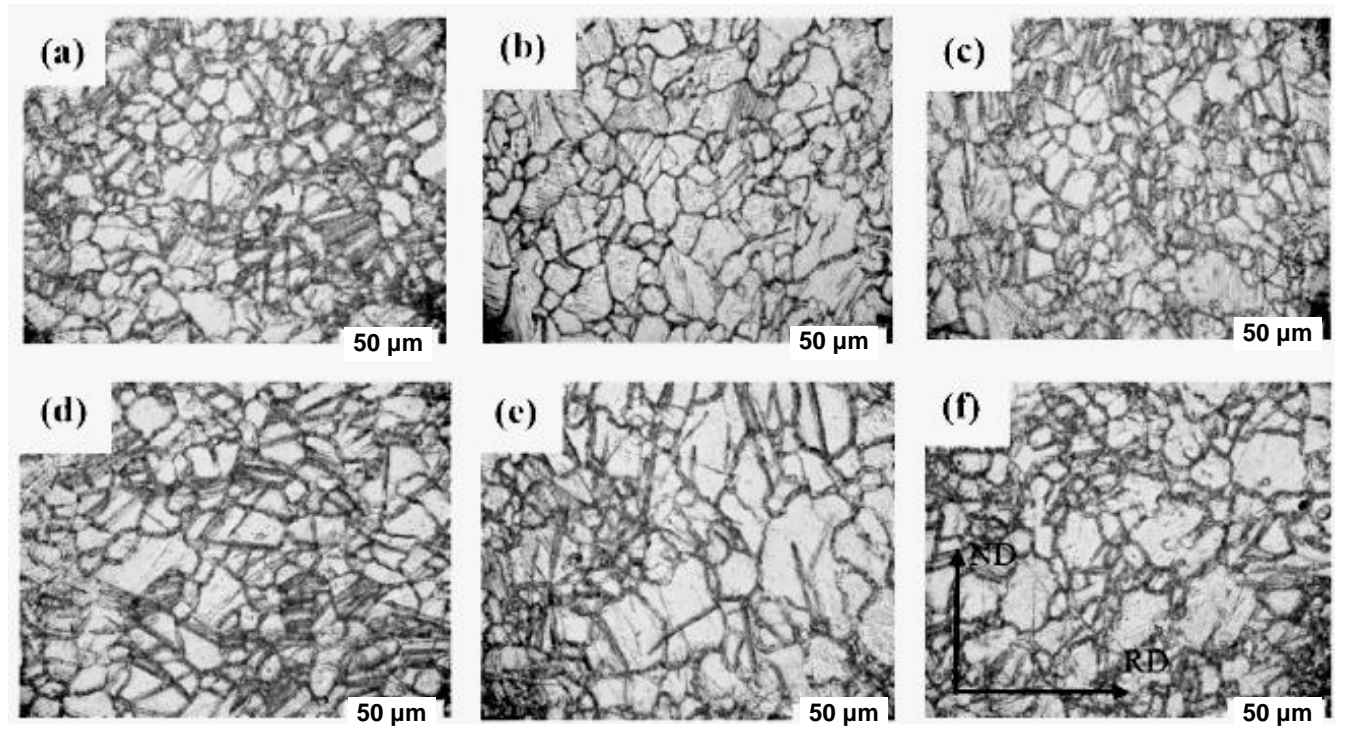

Figure 4 Microstructure of $A Z 31$ after $75 \%$ warm rolling and stress aging under $50 \mathrm{MPa}$ at (a) $120{ }^{\circ} \mathrm{C}$ for $1 \mathrm{~h}$, (b) $120^{\circ} \mathrm{C}$ for $3 \mathrm{~h}$, (c) $120^{\circ} \mathrm{C}$ for $12 \mathrm{~h}$, (d) $180^{\circ} \mathrm{C}$ for $1 \mathrm{~h}$, (e) $180{ }^{\circ} \mathrm{C}$ for $3 \mathrm{~h}$, (f) $180{ }^{\circ} \mathrm{C}$ for $12 \mathrm{~h}$

\subsection{Fracture morphology}

The tensile fracture surface of AZ31 magnesium alloy for different conditions is shown in Figure 5. The surface is characterized by cleavage facets and steps represent a relatively brittle fracture mechanism for all conditions [21]. The fracture surface of the AR sample with a high density of tear ridges and remarkable small dimples depicts a completely different fracture behavior with the rolled conditions (Figure 5a). On the other hand, Figure $\mathbf{5 b}$ demonstrates mixed fracture modes of the stress aged sample, consisting of intergranular fracture of small recrystallized grains and fast fracture of coarse grains formed due to aging induced grain growth.

Also, increasing the duration of aging treatment at $120^{\circ} \mathrm{C}$, from $24 \mathrm{~h}$ to $48 \mathrm{~h}$, increased the density of tears on the fracture surface (Figures $\mathbf{5 c}, \mathrm{d}$ ). This can be attributed to the noticeable intensification of recrystallization with higher aging durations. A similar trend was observed for the samples aged at $180^{\circ} \mathrm{C}$ with a difference in the size of the dimples which are larger than those on the fracture surface of the samples aged at $120^{\circ} \mathrm{C}$ as related to the grain growth of the former (Figures $\mathbf{5 e}$ and $\mathbf{f}$ ). However as shown in Figure $\mathbf{5 f}$, the fast fracture occurring on the cleavage facets prevented the development of dimples on the fracture surface and consequently abrupt failure took place for the sample aged at $180^{\circ} \mathrm{C}$ for $48 \mathrm{~h}$. 

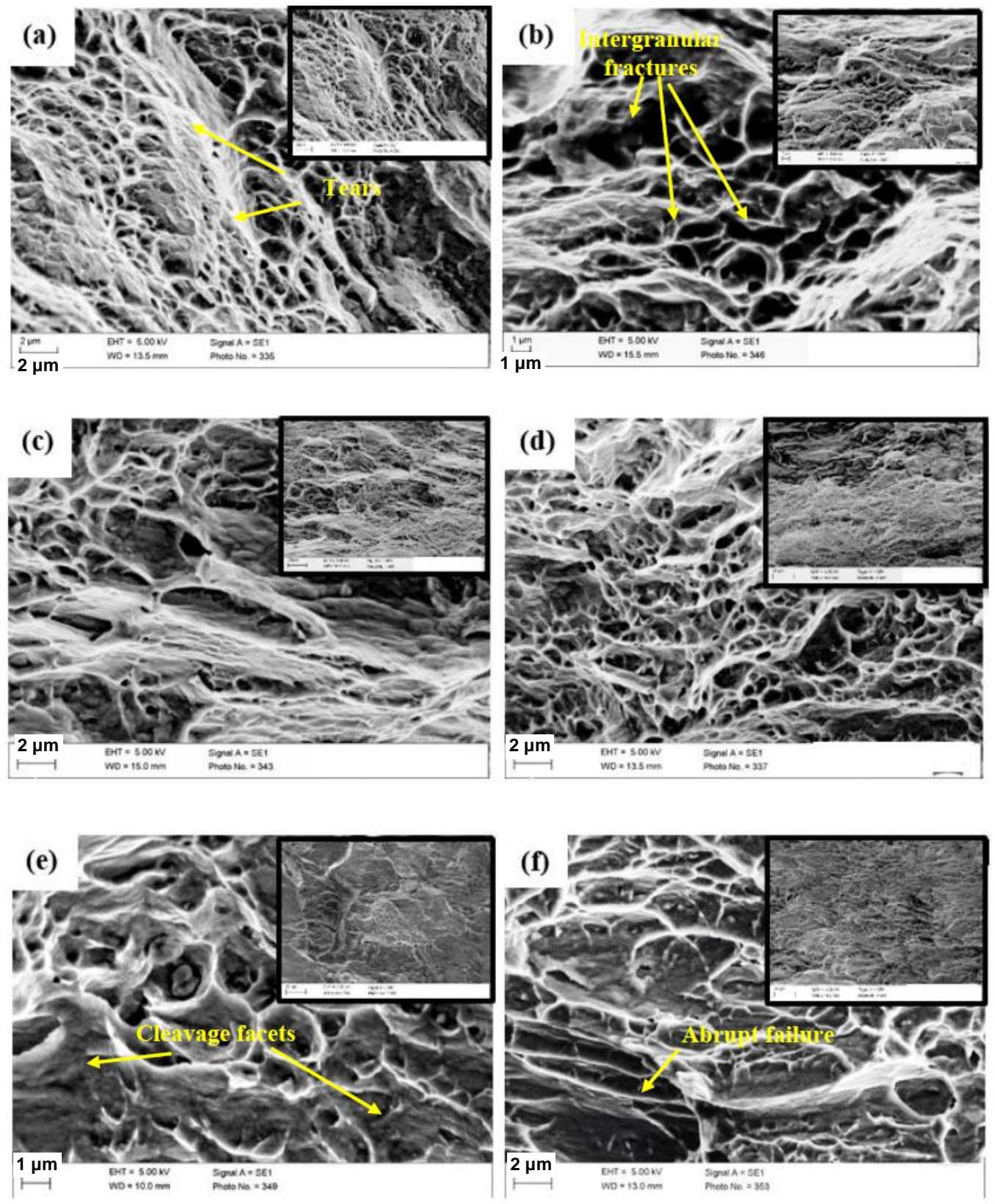

Figure 5 Fracture surface of the AZ31 magnesium alloy for different conditions of (a) AR; (b) $75 \%$ rolled then stress aged under $50 \mathrm{MPa}$ at $120^{\circ} \mathrm{C}$ for $1 \mathrm{~h} ; 75 \%$ rolled then conventional aged at (c) $120^{\circ} \mathrm{C}$ for $24 \mathrm{~h}$; (d) $120^{\circ} \mathrm{C}$ for $48 \mathrm{~h}$; (e) $180^{\circ} \mathrm{C}$ for $24 \mathrm{~h}$; (f) $180^{\circ} \mathrm{C}$ for $48 \mathrm{~h}$

\section{CONCLUSION}

In the current study, different thermo-mechanical processing conditions were applied on the AZ31 magnesium alloy. The results of tensile experiments demonstrated the UTS level of $300 \mathrm{MPa}$ for the sample aged at 120 ${ }^{\circ} \mathrm{C}$ for $24 \mathrm{~h}$ after $75 \%$ rolling. Besides, $48 \mathrm{~h}$ aged sample at $120{ }^{\circ} \mathrm{C}$ improved the strain at failure after rolling up to $13 \%$ because of the nucleation of recrystallized grains and consequent grain growth.

On the other hand, stress aging improved the YS of the AR samples up to $240 \mathrm{MPa}$ without significant negative effect on the strain to failure for the samples stress aged at $120{ }^{\circ} \mathrm{C} 1 \mathrm{~h}$ under $50 \mathrm{MPa}$. This strength improvement was linked to the acceleration of precipitation hardening through the stress aging treatment and consequently particle-stimulated nucleation. In addition, fracture morphology of rolled samples depicts a brittle 
fracture surface with cleavage facets, while a mixture of failure mechanisms encompassing intergranular fracture of small recrystallized grains and fast fracture of coarse grains was observed for the stress aged samples. In addition, a relatively high fraction of tear ridges was observed on the fracture surface of conventional aged samples after $48 \mathrm{~h}$, where fast fracture of coarse grains prevented the formation of dimples.

\section{REFERENCES}

[1] BUSK, R.S. Magnesium products design. Marcel Dekker, Inc. 270 Madison Ave, New York, New York 10016, USA, 1987, $554 \mathrm{p}$.

[2] AVEDESIAN, M. Magnesium and Magnesium Alloys. ASM Specialty Handbook. ASM International, 1999.

[3] SINGH, K., SINGH, G., SINGH, H. Investigation of microstructure and mechanical properties of friction stir welded AZ61 magnesium alloy joint. Journal of Magnesium and Alloys. 2018.

[4] CHAI, F., ZHANG, D., LI, Y. Microstructures and tensile properties of submerged friction stir processed AZ91 magnesium alloy. Journal of Magnesium and Alloys. 2015, vol. 3, no. 3, pp. 203-209.

[5] FATEMI-VARZANEH, S.M., ZAREI-HANZAKI, A., BELADI, H. Dynamic recrystallization in AZ31 magnesium alloy. Materials Science and Engineering: A. 2007, vol. 456, no. 1, pp. 52-57.

[6] CAO, X. et al. A review of laser welding techniques for magnesium alloys. Journal of Materials Processing Technology. 2006, vol. 171, no. 2, pp. 188-204.

[7] AKYUZ, B. Machinability of magnesium and its alloys. TOJSAT: The Online Journal of Science and Technology. 2011, vol. 1, no. 3, pp. 31-38.

[8] SANDERS, P. et al. High power Nd: YAG and $\mathrm{CO}_{2}$ laser welding of magnesium. Journal of Laser Applications. 1999, vol. 11, no. 2, pp. 96-103

[9] LEONG, K. et al. Laser beam welding of AZ31B-H24 magnesium alloy. In International Congress on Applications of Lasers \& Electro-Optics. 1998. LIA.

[10] ANDO, S., Tonda, H. Non-basal slips in magnesium and magnesium-lithium alloy single crystals. In Materials science forum. 2000. Trans Tech Publ.

[11] STOHR, J.F., POIRIER, J.P. Etude en microscopie electronique du glissement pyramidal $\{1122\}\langle 1123\rangle$ dans le magnesium. Philosophical Magazine. 1972, vol. 25, no. 6, pp. 1313-1329.

[12] FRIEDRICH, H.E., MORDIKE, B.L. Technology of magnesium and magnesium alloys. Magnesium Technology: Metallurgy, Design Data, Applications. 2006, pp. 219-430.

[13] SHA, M.-H. et al. Paint-bake response of AZ80 and AZ31 Mg alloys. Transactions of Nonferrous Metals Society of China. 2010, vol. 20, pp. s571-s575.

[14] JEONG, H.T., HA, T.K. Texture development in a warm rolled AZ31 magnesium alloy. Journal of Materials Processing Technology. 2007, vol. 187, pp. 559-561.

[15] UEMATSU, Y., TOKAJI, K., MATSUMOTO, M. Effect of aging treatment on fatigue behaviour in extruded AZ61 and AZ80 magnesium alloys. Materials Science and Engineering: A. 2009, vol. 517, no. 1, pp. 138-145.

[16] SEPEHRBAND, P., LEE, M., BURNS, A. Pre-straining effect on precipitation behaviour of AZ31B. In Magnesium Technology. 2016, Springer. pp. 89-92.

[17] GUO, F. et al. Strain-induced dynamic precipitation of Mg17Al12 phases in Mg-8Al alloys sheets rolled at $748 \mathrm{~K}$. Materials Science and Engineering: A. 2015, vol. 636, pp. 516-521.

[18] LI, X. et al. Influence of second-phase precipitates on the texture evolution of Mg-Al-Zn alloys during hot deformation. Scripta Materialia. 2012, vol. 66, no. 3, pp. 159-162.

[19] TROEGER, L., STARKE E. Jr. Particle-stimulated nucleation of recrystallization for grain-size control and superplasticity in an Al-Mg-Si-Cu alloy. Materials Science and Engineering: A. 2000, vol. 293, no. 1-2, pp. $19-29$.

[20] ROBSON, J.D., HENRY, D.T., DAVIS, B. Particle effects on recrystallization in magnesium-manganese alloys: Particle-stimulated nucleation. Acta Materialia. 2009, vol. 57, no. 9, pp. 2739-2747.

[21] LU, Y. et al. Effects of rare earths on the microstructure, properties, and fracture behavior of Mg-Al alloys. Materials Science and Engineering: A. 2000, vol. 278, no. 1, pp. 66-76. 